\title{
The Effectiveness of Neurological Impress Method on Reading Fluency of Students with Learning Disabilities in Amman, Jordan
}

\author{
Ayed H. Ziadat ${ }^{1} \&$ Mohammad Soud A. AL-Awan ${ }^{2}$ \\ ${ }^{1}$ Department of Special Education, Princess Rahma College, Al-Balqa Applied University, Al Salt, Jordan \\ ${ }^{2}$ Retaal International Academy, Amman, Jordan \\ Correspondence: Ayed H. Ziadat, Department of Special Education, Princess Rahma College Al-Balqa Applied \\ University, Al Salt, Jordan. E-mail: ayedziadat@yahoomail.com
}

Received: August 4, 2017

doi:10.5539/ies.v11n1p165
Accepted: September 22, 2017

Online Published: December 29, 2017

URL: https://doi.org/10.5539/ies.v11n1p165

\begin{abstract}
The aim of this study was to evaluate the effectiveness of Neurological Impress Method (NIM) on reading fluency of students with learning disabilities in Amman, Jordan. A sample of forty students (boys and girls) between the ages 10-12 years old with learning disabilities were selected from the Fourth Amman Educational Directorate in the Hashemite Kingdom of Jordan.
\end{abstract}

Students focused groups in this research were separated into two different groups including the satisfactory controlled group. The participants were taught for one complete semester. Two hypotheses were formulated to guide this research.

Statistical analysis to the gathered data revealed that the focused group of students who were trained according to the scheduled strategy to improve students reading ability or became more fluent in reading.

Full analyses were applied using the T-test on all available data, indicating that students who were trained according to the scheduled strategy.

The study found out that the strategy reduced the reading fluency deficiency in teens with different levels of learning disabilities. Consequently, it was recommended that the strategy can be used to improve reading fluency of students with learning disabilities.

Keywords: classification, effectiveness, Jordan, learning disabilities, NIM, reading fluency

\section{Introduction}

Learning disabilities are problems that may affect the brain's ability to receive, process, analyze, or store information. These issues make it hard for a student to learn as quickly as someone who isn't affected by learning disabilities (Oladele, 2013).

Many researches indicate that there are a staggering number of disability cases occurring worldwide according to many different reasons.

To be able to read is a basic fundamental for a student to succeed in the classroom, despite the fact that reading is a complex process. Students with learning disabilities have problems in comprehending what they read and what they have learned on the long span process without support. That due to the difficulties they may face while they are processing information.

Such students can be identified by the fact that they can't comprehend at similar level and rate like their peers of their age in the same classroom. The complications of students with learning disabilities revolve to be more complicated especially at public schools as most teachers are not equipped and trained with specialized techniques that are required for students with learning disabilities (Oladele, 2013; Barden, 2009; Hasbrouck \& Tindal, 2006, and Omotoso, 2001).

The school's curriculums in Jordan are designed for general academic needs of all students without any considerations to students with learning disability. Such categories of students usually face difficulties in reading fluency and comprehension leading to their lacking behind in comparison to other normal students in the classroom. Despite the location and the education levels, many researchers worldwide acknowledge the fact that 
learning disability is a universal problem (Young, 2011; Ming \& Dukes, 2008; Spear-Swerling, 2006). The researchers used the school's curriculums to debate the research in the chosen schools.

Moreover, this research focused on fluency in reading due to the fact that most of the students with learning disabilities are faced with challenges not only in the reading area but also in other school subjects. In addition, Ming and Dukes 2008 stated that the general classroom dynamics paid more attention to reading comprehension rather than the reading fluency. So, the researchers decided to focus on this method (Neurological Impress Method) and investigate its effectiveness especially many studies recommended and found its importance to use it with students with learning disabilities.

The intervention strategy used in this research is the Neurological Impress Method (NIM). This method relies on more of concentrations on reading loudly from both the teacher and the student at the same time repeatedly and directly with the teacher in order to stay at the same rhythm of the teacher tone with every repeated statement keeping in mind that this strategy requires a quiet environment.

Nelson \& Gordy 2004, Flood \& Fisher 2005, and Barden 2009 confirmed this approach as approved technique for teaching reading fluency to students with learning disabilities.

Many researchers worldwide showed satisfaction with the results of the Neurological Impress Method (NIM) developed as very prevalent method with sufficient techniques for practicing reading fluency to students with reading disabilities (Heckerman, 1986; Chard \& Tyler, 2002; Feazell, 2004; Flood \& Fisher, 2005; Wise, 2007 nd Barden, 2009).

\section{Statement of the Topic}

Educators in public schools of Jordan evidently showed a limited mastery of the technical methodical approach, and the effective ways of dealing with students with learning disabilities in regular classrooms. This can be attributed to the inadequacy of professional training and in-service training workshops/seminar for teachers. Due to this inadequacy, the majority of teachers can hardly identify such students and even when they do, they assume that such students must act and obtain knowledge just like all other normal students in the classroom.

The study therefore introduces the NIM in the Jordan educational community with the hope of showing its efficacy in the reading fluency of students with learning disabilities. The method was applied as a modern proposal to improve the reading fluency of students with learning disabilities in four public primary schools in Amman in particular and Jordan as a whole.

Forty students between (10-12) years old with learning disability were involved in the study. The participants comprised of twenty boys and twenty girls in comparison to a controlling group of normal students in the same classrooms with the exact controlling environmental conditions.

The research used the statistical hypothesis with no significant differences $(\mathrm{a}=0.5)$ reading fluency of students with learning disabilities revealed to the NIM with gender differences, and also no significant differences ( $\mathrm{a}=$ 0.5 ) in the reading fluency of the Neurological Impress Method groups and the control group.

\section{Research Methodology}

Two experimental groups and one control group were used in this study. Each group consisted of twenty students (ten boys and ten girls) in the fourth grade in four different schools. The control group didn't receive any treatment. Students were initially identified as having reading fluency difficulties during the pre-test and according to the Savath College Diagnostic Test which is used to classified those students who have learning disabilities in reading, writing Arabic and math. The student has to read a paragraph according to his age and level. If he couldn't or face a problem, then he gave a text below his age (two years). All parents consented to the participation of their students in this study. Four experienced teachers who taught students with learning disabilities in the four public schools were selected and trained for one week on how to effectively intervene using the Neurological Impress Method for reading fluency with these students keeping in mind that targeted students groups (experimental groups) were taught by the same teachers chosen and who they were already familiar with them.

To conduct this experimental work in four public schools, a permission from the Ministry of Education in Jordan was granted prior the study and during the academic year 2016/2017. The teaching sessions took place five days a week for 45 minutes about sixteen weeks between (February-May). The students were originally addressed by the class teachers as poor readers; they were also classified with incapacities according to Savath College Diagnostic Test and confirmed at the resource rooms of the schools district at Marka District Directorate in Jordan. 
For the pre-test, two unread passages consisting of 85 words were chosen from the curriculum and read aloud by the students to their teachers for 15 minutes for each passage. The same passages used for the pre-test were also used for the post-test. A tabulated format was developed to evaluate the weekly improvements of the treated students as the training was customized for these two groups of students only. Scores of the pre-test reveled that all students were reading at 2 degrees lower than their anticipated reading level, based on the categories of Savath College Diagnostic Test. During each experimental class session with the students with reading disabilities, the Neurological Impress Method was applied. The student sat slightly in front of the teacher so that the voice was clear and direct to the student's ear. The student was asked to focus and not to be distracted by any of the surroundings. He/she was asked to just read along with the teacher's voice. The student and teacher read together, with the teacher using lots of expressions. The teacher didn't stop to correct the student. Where and when the student read a portion poorly, he/she simply reread it again until improvements were visible or obtained. It is important to observe here that, the focus was not on accuracy but on fluency.

The study population consisted of students with learning disabilities from the fourth Amman Educational Directorate in the Hashemite Kingdom of Jordan. Table (1) below shows the numbers of male and female students groups, with a total of twenty students according to the pre-test and post-test. This category was put after the implementation of the Neurological Impress Method for reading fluency.

Table 1. Demographic variables of the study sample (Gender).

\begin{tabular}{lccc}
\hline Student Groups & \multicolumn{2}{c}{ Gender } & Total \\
\hline & Male & Female & \\
\cline { 2 - 3 } Control Group/Pre-test & 10 & 10 & 20 \\
Experimental Group/Pre-test & 10 & 10 & 20 \\
Control Group/Post-test & 10 & 10 & 20 \\
Experimental Group/Post-test & 10 & 10 & 20 \\
Total & 40 & 40 & 80 \\
\hline
\end{tabular}

The current research consists of two aspects; theoretical and practical. In the theoretical aspect, the researchers relied on the scientific studies that are related to the topic of this research using the practical approach to gather, analyze data, and response the questions.

The current research is based on two sources:

Main Source: a set of questions which was intended to represent the study main objectives, including questions, and participants responses.

Secondary Sources: books, journals were used to initiate the background outline of the study.

Program: This was built according to their level and from the curriculum which was adapted in the Hashemite Kingdom of Jordan. The researchers adapted the curriculum which was obtained and used for all students in the public schools in Jordan. The experimental group worked for four months. They also used the same text throughout for the fourth grade in Jordan.

A full review of the most recent published research regarding behavior and attitudes of students with learning disabilities in the Middle East and especially in Jordan were reviewed and followed by data collected from a specially formulated questionnaire for this research and for the intention of this work.

The questionnaire instrument can be divided into two sections as follows:

Scores were calculated using Likert Scoring procedures as recommended by Golderg (1972)

This section was measured through twenty items on a Likert-type scale as follows:

\begin{tabular}{|c|c|c|}
\hline Excellent & Good & Bad \\
\hline 3 & 2 & 1 \\
\hline
\end{tabular}

In order to evaluate the students' performance before and after implementing the Neurological Impress Method on the chosen students with learning disabilities, twenty questions were developed attach as appendix clearly identifying what aspect each of the questions addressed and the responses to these questions were evaluated. Such questions and the level of improvements according to the teacher's evaluations of the students with learning disabilities reflected on many aspects of the students improvements in their reading fluency before and after the implementation of the Neurological Impress Method. The Statistical Package for Social Sciences (SPSS) 
was used to evaluate the collected data. The Standard Deviation, Arithmetic Mean, analysis of Co-Variance Two Way ANOVA and the Two Way ANCOVA statistical analyses were used on the data collected from the questionnaire. Relative importance, assigned due to:

$$
\begin{gathered}
\text { Class Interval }=\frac{\text { Max.Class }- \text { Min.Class }}{\text { Number of Levels }} \\
\frac{3-1}{3}=\frac{2}{3}=0.66
\end{gathered}
$$

The Min. degree from 1- 1.66

The Medium degree from $1.67-2.33$

The Highest degree from $2.34-3.00$

The questionnaire was evaluated by ten professionals from different Jordanian Universities specialized in education for its subject matter, simplicity of language, and suitability of the parts prior to implementing the study using a preliminary draft form. Some questions were added, modified, or formulated while other questions were dropped based on the reviewer valuable comments and recommendations in order to enhance the research instrument. The developed questions were consequently appreciated based on the pre-test in order to match the objectives of this research. The test-retest reliability coefficient $(\alpha)$ was used to test the reliability, and the consistency of the questions, which was measured to be $(0.73)$. This is a responsible result as it exceeds 0.60 (George \& Mallery, 2003).

\section{Purpose of the Study}

The purpose of this study was to investigate the efficacy of the (NIM) on the reading fluency of children with learning disabilities in four public primary schools in Amman, Jordan.

\section{The importance of the Study}

The study is important because the (NIM) was successfully used as intervention strategy to improve the reading fluency of 40 students with learning disabilities Amman, Jordan.

The study also sensitized some regular public primary school teachers to the fact that they used to plan intervention strategies to address the reading fluency problems experienced by children with learning disabilities in particular and all other children with reading problems in their classrooms.

\section{Hypotheses of the Study}

The objective of this work was to determine the impact of using the Neurological Impress Method on students with learning disabilities. The following hypotheses were applied:

Hypothesis I: the first hypothesis to this study is as follow:

"No significant difference to be shown in the reading fluency of the Neurological Impress Method groups and the control group?"

The study used the arithmetic mean, standard deviation, and Two Way ANCOVA test to show the result about the statistical significant difference between experimental and control group, as follows:

Table 2. The Mean and S.D for Pre, and Post Measurements using the NIM among the sample groups. We measured here the Pre. and Post. Reading Test by using the (NIM) among a sample groups

\begin{tabular}{lcccccc}
\hline \multirow{2}{*}{ Source } & \multicolumn{3}{c}{ Pre-Test } & \multicolumn{3}{c}{ Post-Test } \\
\cline { 2 - 7 } & Mean & Std. Deviation & Number & Mean & Std. Deviation & Number \\
\hline Controlled Group & 1.79 & 0.29 & 20 & 1.84 & 0.25 & 20 \\
Experimental Group & 1.68 & 0.26 & 20 & 2.44 & 0.30 & 20 \\
Total & 1.73 & 0.28 & 40 & 2.14 & 0.41 & 40 \\
\hline
\end{tabular}

Table 2 shows that mean for controlled group in pre-test reading was 1.79 with standard deviation 0.29 , the mean for experimental group in pre-test reading was 1.68 with a standard deviation of 0.26 . Meanwhile the mean for controlled group in post-test reading was 1.84 with a standard deviation of 0.25 , and the mean for experimental 
group on post-test reading was 2.44 with standard deviation 0.30 .

To identify the statistical significant differences, the Two Way ANCOVA test, was applied and the results tabulated as shown in Table 3.

Table 3 shows that (F) value for group was (46.54), and it's significant at level of (0.05), this explains that there were statistically significant differences among the different students groups (controlled and experimental in the post measurement) and the variance was in favor of the post measurement for the experimental group, this result can be attributed to the implementation of the Neurological Impress Method and the students with learning disabilities.

Table 3. Two ways ANCOVA test to identity the statistical differences between the groups

\begin{tabular}{cccccc}
\hline Source & Type III Sum of Squares & Df & Mean Square & F & Sig. \\
\hline Corrected Model & 3.57 & 1 & 3.57 & 46.54 & 0.000 \\
Intercept & 183.39 & 1 & 183.39 & 2391.29 & 0.000 \\
Group & 3.57 & 1 & 3.57 & 46.54 & $0.000^{*}$ \\
Error & 2.91 & 38 & 0.076 & & \\
Total & 189.88 & 40 & & & \\
Corrected Total & 6.48 & 39 & & & \\
\hline
\end{tabular}

* Significant at level (0.05).

Hypothesis II;

The second hypothesis applied in this research is as follow:

"No significant difference in the reading fluency of students with learning disabilities exposed to the Neurological Impress Method and gender".

The study used the arithmetic mean, standard deviation, and Two Way ANOVA test to show the results regarding the statistically significant difference between experimental groups of students and control group students in their reading according to the (NIM) on the post measurement, as shown in Table 4.

Table 4. Mean and standard deviation for pre, and post measurements in their reading fluency of students with learning disabilities exposed to the NIM and gender

\begin{tabular}{|c|c|c|c|c|}
\hline Source & Gender & Mean & Std. Deviation & $\mathrm{N}$ \\
\hline \multirow{3}{*}{ Controlled Group } & Male & 1.97 & 0.26 & 10 \\
\hline & Female & 1.72 & 0.17 & 10 \\
\hline & Total & 1.84 & 0.25 & 20 \\
\hline \multirow{3}{*}{ Experimental Group } & Male & 2.64 & 0.18 & 10 \\
\hline & Female & 2.24 & 0.26 & 10 \\
\hline & Total & 2.44 & 0.30 & 20 \\
\hline \multirow{3}{*}{ Total } & Male & 2.31 & 0.41 & 20 \\
\hline & Female & 1.98 & 0.34 & 20 \\
\hline & Total & 2.14 & 0.41 & 40 \\
\hline
\end{tabular}

Table 4 shows that there were differences in the Means in the reading fluency of students with learning disabilities exposed to due to gender, and the study used Two Way ANOVA test to identify the statistical significant differences, as shown in Table 5. 
Table 5. Two way ANOVA test significant difference in the reading fluency of students with learning disabilities exposed to the NIM and gender

\begin{tabular}{|c|c|c|c|c|c|}
\hline Source & Type III Sum of Squares & Df & Mean Square & $\mathrm{F}$ & Sig. \\
\hline Corrected Model & $4.695^{\mathrm{a}}$ & 3 & 1.56 & 31.48 & 0.000 \\
\hline Intercept & 183.39 & 1 & 183.39 & $3.690 \mathrm{E} 3$ & 0.000 \\
\hline Group & 3.57 & 1 & 3.57 & 71.83 & $0.000 *$ \\
\hline Gender & 1.07 & 1 & 1.07 & 21.58 & $0.000 *$ \\
\hline Group * Gender & 0.05 & 1 & 0.05 & 1.058 & 0.311 \\
\hline Error & 1.78 & 36 & 0.05 & & \\
\hline Total & 189.88 & 40 & & & \\
\hline Corrected Total & 6.48 & 39 & & & \\
\hline
\end{tabular}

* Significant at level (0.05).

Table 5 shows that (F) value for the group was (71.83) and its significant at level of $(0.05)$. The (F) value for gender was calculated as (21.58), and its significant at level of (0.05), and the differences was in favor of males students with learning disabilities', as shown in the previous table. According to the results, the Neurological Impress Method was more effective with male's students more than the females' students with learning disabilities.

\section{Results and Discussion}

The results of this research showed that the Neurological Impress Method is a respectable influence instrument that can be applied successfully to instruct reading fluency for students with learning disabilities. The Neurological Impress Method as an effective technique for reading fluency intervention for students with reading disabilities. This is in full agreement with other researchers who conducted similar research in different parts of the world (Nelson et.al. 2004, Barden 2009). Many variables can be used in this method to solidify causes consequence relationship among reading fluency and comprehension (Young, 2011). On the other hand, this research provided clear evidence that the controlled group students who didn't receive the Neurological Impress Method and they were not exposed to any intervention showed no improvements.

\section{Conclusion and Recommendations}

To summarize, reading fluency is a carousal segment of the reading techniques, with significant possibility that such problems will attribute to further difficulties and also affect reading comprehension and all other fields of reading. It is desirable for students with learning disabilities to become better readers after frequent training and regular repeated practicing. Educators at different levels and teachers should pursue to apply the (NIM) for teaching reading fluency to students with learning disabilities. It is worth mentioning that students with learning disabilities deserve more attention and care from teachers in order to improve the capabilities of fluency at different levels of education specially that the majority of such students are usually characterized as hyper-active students. It is essential to improve the applications of the Neurological Impress Method in different public schools in the Hashemite Kingdom of Jordan and the other Middle Eastern countries.

\section{References}

Barden, O. (2009). From acting reading to reading for acting: A case study of the transformational power of reading. Journal of Adolescence and Adult Literacy, 53(4), 293-302. https://doi.org/10.1598/JAAL.53.4.3

Chard, D. J., Vaughan, S., \& Tyler, B. J. (2002). A synthesis of research on effective in intervention for building reading fluency with elementary students with learning disabilities. Journal of Learning Disabilities, 35(5), 386-406. https://doi.org/10.1177/00222194020350050101

Feazell, V. (2004). Reading accelerated program: A school wide intervention. International Reading Association, 58(1), 66-72.

Flood, J., Lapp, D., \& Fisher, D. (2005). Neurological Impress Method plus. Reading Psychology: An International Quarterly, 26(2), 147-160.

Freedman, V. A., Martin, L. G., \& Schoeni, R. F. (2004). Disability in America. Population Bulletin, 5(3), 3-32.

George, D., \& Mallery, P. (2003). SPSS for Windows step by step: A simple guide and reference (4th ed.). Boston: Allyn \& Bacon.

Goldberg, D. (1972). The detection of psychiatric illness by questionnaire. Oxford University Press. 
Hasbrouck, J., \& Tindal, G. A. (2006). Oral Reading Fluency Norms: A valuable Assessment Tool for Reading Teacher. The Reading Teacher, 59(7), 636-644. https://doi.org/10.1598/RT.59.7.3

Heckleman, R. G. (1986). Neurological Impress Method revisited: An update on the Neurological Impress Method and the Presenting techniques. Academic Therapy, 21, 411-421.

Langenberge. (2000). Report of the National Reading Panel: Teaching Students to read (Reports of the sub groups). Washington, D.C National Institute of Students Health and Human Development.

Learning Disabilities Association of America. (1998). Reading methods and learning disabilities. Pittsburg: LDA New briefs March- April 38 No. 4.

Ming, K., \& Dukes, C. (2008). Fluency: A necessary ingredient in comprehensive reading instruction in inclusive classrooms. Teaching Exception Students Plus, 4(4), 1-14.

National Reading Panel. (2002). Teaching students to read: An evidence based assessment of the scientific research literature on reading and its implication for reading instructions. Washington. D.C: National Institute of Child Health and Human Development.

Nelson, J. S, Alber, S. R., \& Gordy, A. (2004). The effects of error correction and repeated reading on the reading achievement of students with learning disabilities. Educational and Treatment of Students, 27, 186-198.

Oladele, A, O. (2013). The Efficacy of Neurological Impress Method and Repeated Reading on Reading Fluency of Students with Learning Disabilities in Oyo State, Nigeria. World Academy of Science, 7(1).

Omotoso, J. A. (2001). Learning disability problems prevalent among elementary school age students in Ilorin metropolis: Implications for special education and counseling. Ife psychological, 9, 128-133.

Spear-Swerling, L. (2006). Preventing and remediating difficulties with reading fluency. Retrieved from https://www.idonline.org.spearswerling/8811

Wise, B. W., \& Snyder, L, (2007). Clinical Judgments in Identifying and Teaching Students with Language based Reading Difficulties. USA: National Research Center on Learning Disabilities.

Young, C. (2011). Reading fluency and implicit comprehension: Implications for research and instruction. https://www.thebestclass.org/index.html

\section{Copyrights}

Copyright for this article is retained by the author(s), with first publication rights granted to the journal.

This is an open-access article distributed under the terms and conditions of the Creative Commons Attribution license (http://creativecommons.org/licenses/by/4.0/). 